\title{
Associated Use Attainment Response between Multiple Aquatic Assemblage Indicators for Evaluating Catchment, Habitat, Water Quality, and Contaminants
}

\author{
Thomas P. Simon ${ }^{1}$ and Charles C. Morris ${ }^{1,2}$ \\ ${ }^{1}$ Department of Biology, Indiana State University, 600 Chestnut Street, Terre Haute, IN 47809, USA \\ ${ }^{2}$ Indiana Dunes National Lakeshore, U.S. Department of the Interior, 1100 North Mineral Springs Road, Porter, IN 464304, USA
}

Correspondence should be addressed to Thomas P. Simon; thomas_simon@juno.com

Received 30 May 2014; Revised 17 August 2014; Accepted 6 September 2014; Published 15 October 2014

Academic Editor: Wen-Cheng Liu

Copyright (c) 2014 T. P. Simon and C. C. Morris. This is an open access article distributed under the Creative Commons Attribution License, which permits unrestricted use, distribution, and reproduction in any medium, provided the original work is properly cited.

\begin{abstract}
Use attainability analysis (UAA) at a watershed scale typically relies on the assumption that indicator organisms are responding similarly to the same environmental stressor. Factors explaining variance in fish, crayfish, and macroinvertebrate assemblage structure and function were investigated with emphasis on catchment and reach scale land use, habitat, contaminants, and water quality variables. Habitat quality scores ranged from 25 to 85 (average $61.36 \pm 10.08$ ). The substrate score, instream cover, rifflerun score, and channel score were primary factors contributing to declining habitat quality. Factor analysis found that four factors explained $69 \%$ of the contributed variance in fish assemblage, two factors accounted for $56 \%$ of variance in macroinvertebrate assemblages, and two factors explained $49 \%$ of the variance in crayfish assemblages. Overall drivers of assemblage structure were associated with broad scale issues of wastewater treatment, groundwater, and land use. Our results show that fish, macroinvertebrate, and crayfish assemblages respond to similar broad scale stimulus; however, the specific constituents responsible for the stress may vary with the magnitude of the cumulative stress, which may be expressed by each organismal group differently. Our data suggest that varying organismal groups can respond independently and stress reflected in one assemblage may not necessarily be observed in another since each organismal group is measuring different aspects of the environment.
\end{abstract}

\section{Introduction}

Regional scale use attainability analysis (UAA) is a structured scientific assessment of the factors affecting the fulfillment of the fishable/swimmable goals of the United States Clean Water Act (Section 101(a)(2)). Watershed use attainment is determined by evaluating multiple indicators occurring within the same reach and exposed to the same stressors. The assumption is that various trophic level biological indicators will respond similarly to stressors $[1,2]$. Many state and federal agencies assume that biological assemblages are measuring the same features of the environment $[3,4]$. Oftentimes, the response between various indicators is divergent or contradictory, which has been attributed to differing trophic level impact to chemical, land use, and habitat characteristics [2]. When agreement between indicators is not achieved, the UAA created an elaborate interpretation to describe disagreement between biological assemblage indicators. This has resulted in statements of full support, partial support, indeterminate, or not meeting aquatic life designated uses.

The factors considered for determining when UAA does not meet beneficial use include the physical, chemical, biological, and economic use criteria in EPA's water quality standards regulation (40 CFR 131.10(g)(1)-(6)). Under Section 40 CFR $131.10(\mathrm{~g})$, demonstration of nonattainment of designated uses can be attributed to five conditions that prevent stream reaches from not meeting aquatic life uses. Nonattainment can be because of naturally occurring pollutant concentrations that prevent the attainment of the use. These causes can be a result of natural, ephemeral, intermittent, or low flow conditions or water levels that prevent the use attainment. Another reason could be human caused conditions or sources of pollution that prevent use attainment and cannot be remedied or would cause more environmental damage to 
correct the condition than to leave in place. Dams, diversions, or other types of hydrologic modifications preclude the attainment of the use, and it is not feasible to restore the water body to its original condition or to operate the hydrologic modification in a way that would result in the use attainment. Physical conditions related to the natural features of the water body, such as the lack of a proper substrate, cover, flow, depth, pools, and riffles, are unrelated to water quality and preclude attainment of aquatic life protection uses. A final control would include more stringent conditions than those required by Sections 301(b) and 306 of the act that would result in substantial and widespread economic and social impact.

Previously, assemblage response to stressors did not include contaminant or water quality models that evaluated synergistic effects or sporadic spikes, which can adversely affect biological assemblage structure [3,4]. These factors potentially result in a biologic impairment without the occurrence of specific chemical criteria violations. Suter et al. [3] outlined a formal strategy for causal development that begins with the review of existing data, as well as consultation with stakeholders, to develop a list of candidate causes. Morris et al. [4] determined that resource and regional data availability was usually inadequate to account for contributed causes to impaired biologic communities. Morris et al. [4] identified problems with the development of source identifications for impaired biological communities (IBC). These stressors were not always identifiable and were often overlooked when dealing with observational or qualitative data $[3,5]$.

The need to identify causality for IBC and identify stressor response required evaluation of decision-making processes for determining attainment [6]. The determination of when aquatic life uses were met varies at the individual state level based on a wide variety of measures that only sometimes include biological assemblage data. EPA recommends that two organismal indicator groups be used to determine attainment. Difficulty in tracking whether organisms respond similarly to pervasive nonpoint source impacts, combined with the lack of predetermined signatory relationships with biological assemblage patterns, creates a more complex problem. Morris et al. [4] constructed signatory relationships using multivariate analysis based on definable relationships between aquatic assemblage structure and quantifiable environmental stressors. Simon and Morris [7] used this approach to identify stressor response between contaminants, land use, and crayfish assemblage structure in a mixed use watershed, while Morris and Simon [8] refined the stressor model to predict relative contribution of each stressor type to cumulative explained variance. Norton et al. [9] used multivariate and correlation analysis to demonstrate relationships between ambient chemical, physical, and biological data, while Yoder and Rankin [1], Yoder and DeShon [2], Simon [6], Norton et al. [9], Eagleson et al. [10], and Rive-Murray et al. [11] determined biological response signatures patterns and cause-andeffect relationships. These studies confirm that individual aquatic assemblages respond to different types of stress in ways that are consistent and distinctive. These biological response relationships could be used for future hypothesis

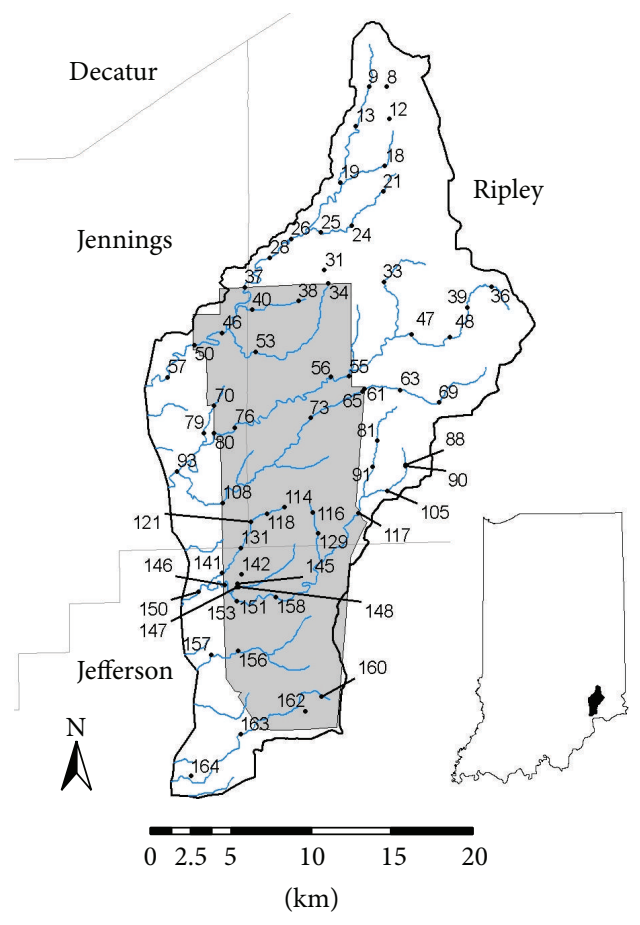

FIGURE 1: Map showing the distribution of sites sampled both on refuge and upstream during a stressor identification assessment of the Big Oaks National Wildlife Refuge in 2006 and 2007 (site numbers refer to Tables B and C). Black line indicates watershed boundary within the study area. Blue lines represent the lotic stream system, and the gray area is the boundaries of the Big Oaks National Wildlife Refuge.

testing; however, no studies comparing indicator patterns have previously been conducted using multiple assemblages associated with the same reach scale stressor exposure.

This project evaluated three aquatic indicator groups and response to varying environmental conditions. Our research question is whether indicators should be expected to respond in a predictable manner across all stressor categories or whether each indicator will respond differentially to response drivers. This question provides the basis for decision-making criteria in UAA. Multiassemblage responses to varying catchment and reach scale land use, habitat, contaminants, and water quality were compared to evaluate patterns in indicator response. The responses of multiple assemblage populations were evaluated using a stressor identification model to determine ecosystem level drivers that provide causal relationships among stressors $[4,8]$.

\section{Methods and Materials}

2.1. Study Area. The Big Oaks National Wildlife Refuge encompasses 20,639 ha of the former Jefferson Proving Ground (JPG) (Figure 1). The former JPG was established in 1940 and was operated as a munitions testing facility until 1995. Portions of the study area were primarily used to test ammunition components, ordnance, and propellant ammunition weapons systems. The former military base has documented impairments from exploded ordnances and metal 
contamination. Since 2000, the U.S. Fish and Wildlife Service have utilized the northern portion of JPG for ecosystembased management in conjunction with continued use by the U.S. Department of Army and Indiana Air National Guard for air-to-ground training.

2.2. Study Design. A stratified, random design [12] was used to select 75 reaches in the Big Oaks National Wildlife Refuge based on the Strahler stream order. Each stream reach within the study area was assigned a numeric code to uniquely identify each reach. These reaches were equally weighted so that the fewer higher stream order reaches were equally weighted for selection with respect to the more numerous lower order reaches. A computer generated algorithm randomly selected 75 reaches without replacement from the universe of potential reaches. Reaches included in the study represented streams that drained locations within the refuge and those on the same streams upstream and downstream on private lands. All sites were visited during spring reconnaissance; those that were dry were excluded from further analysis as were sites that had water but had no aquatic life present. Remaining sites were analyzed for biological assemblage structure with the chemical, physical, and land use data following Simon and Morris [7]. Sample distance was 15 times the wetted stream width with the minimum distance $50 \mathrm{~m}$ and maximum distance $500 \mathrm{~m}$ [13]. Sample distance intervals increased in $50 \mathrm{~m}$ increments with increasing stream widths; for example, sample distance for wetted streams widths 0.1 to $\leq 3.3 \mathrm{~m}$ is $50 \mathrm{~m}$ linear distance, for widths $>3.4 \mathrm{~m}$ to $6.6 \mathrm{~m}$ is $100 \mathrm{~m}$ linear distance, for widths $>6.7 \mathrm{~m}$ to $\leq 10 \mathrm{~m}$ is $150 \mathrm{~m}$ linear distance, and for widths $>10 \mathrm{~m}$ to $\leq 13.3 \mathrm{~m}$ is $200 \mathrm{~m}$ following increasing sequence. Sampling distances of 11 to 15 stream widths are generally adequate to sample a single habitat cycle [13].

2.3. Field Sampling. Fish and macroinvertebrate assemblages are recommended trophic levels for monitoring UAA by the EPA. We selected crayfish since they occupy both aquatic and the terrestrial riparian areas that interface wetland habitats [6-8]. Crayfish are important ecosystem engineers that structure the benthic assemblage structure within streams. Daytime, single-pass fish assemblage inventories were conducted using a Smith-Root 2.5 GPP 150-meter long-line electrofishing system [13]. The long-line system had the capacity of generating $500 \mathrm{v}, 3$ amps, and 2500 watts. Electrofishing surveys are the only preferred method for sampling the species richness, species composition, and relative abundance of fish assemblages in the Midwestern United States because of the high species richness of warm water streams and the associated habitat complexity. Sampling time was dependent on habitat complexity, but representative samples were collected within 300-1500 s. Fish identified in the field were vouchered for later taxonomic verification, while all other specimens were preserved in $10 \%$ formalin for laboratory identification using standard taxonomic references [14-16].

Crayfish sampling included the evaluation of primary, secondary, and tertiary burrowers following Simon [17]. Stream reaches were consistent with macroinvertebrate and fish collection areas and included a variety of survey techniques. Burrowing crayfish were collected by first attempting to coax individuals from the burrows by pouring water down the burrow and agitating the water. If the crayfish failed to emerge, a plunger was used to force the crayfish from the burrow. If that failed to dislodge the crayfish, a hand shovel was used to excavate the burrow and retrieve the individual. Secondary and tertiary burrowers were collected using a backpack electrofishing unit and by turning over large rocks in the stream. Many secondary burrowers are located beneath large stones. By flipping over these rocks, the crayfish can be easily collected by net or hand. All crayfish species collected from each stream reach were composited to estimate relative abundance based on a standardized catch-per-unit effort. Specimens were vouchered for taxonomic verification in $70 \%$ ethanol using standard references $[18,19]$.

Daytime macroinvertebrate assemblages were sampled using a "representative habitat sampling" procedure developed for streams in the Northern Lakes and Forest Ecoregion [20]. A long-handled net shaped like the letter D (D-net) was used to collect 20 efforts within site reach length boundaries and was composited and preserved in 95\% ethanol for laboratory sorting. Efforts were established that, would reflect the abundance of predominant habitats. For example, habitats were segregated into rock, fines, overhanging vegetation, woody debris, coarse particulate material, and other categories. If rocky riffle habitat represented $50 \%$ of the habitat within the stream reach, then 10 of the 20 efforts would be collected in that particular habitat type. Each single effort was based on a 60-second sample using the D-net.

Samples were brought to the laboratory and placed into a $250 \mathrm{~mm} \times 250 \mathrm{~mm}$ gridded sorting pan. A 300-organism count sort was done using a random number generator to reflect the appropriate square to be sorted [2]. Sorting was done until 300 organisms were picked; however, if a square contained the 300th individual, the remainder of that square was sorted until it was fully picked. At the completion of the 300-organism sort, a 15-minute large-rare pick was done. These specimens were identified and used in richness metric calculations but were not included in the trophic or relative abundance metrics. All individuals were identified to the lowest possible taxonomic levels following the state-of-theart for that particular taxon [21-24].

2.4. Physical Habitat, Land Use, Water Quality, and Contaminant Sample Collection. The Qualitative Habitat Evaluation Index (QHEI) is a habitat assessment procedure developed by the Ohio Environmental Protection Agency to determine the quality of site habitat $[25,26]$. The QHEI was used to evaluate habitat condition at each sample location and includes attributes of stream habitat that are typical of Midwestern North American warm water systems. These attributes are divided into a series of five categories and typically three or more subcategories within each category. For example, categories include substrate composition, stream cover habitat, riparian corridor quality, riffle and pool quality, and stream gradient, while subcategories of substrate composition include the variety of sediment particle sizes, embeddedness, siltation, and measures of sedimentation. Each category 
has a series of scalar categories with corresponding scores that describe the range of quantitative or qualitative classes for each variable. The five categories each summed to a maximum of 20 points and the cumulative QHEI site score sums to 100 points. Scores above 66 are considered excellent, while scores above 45 are considered habitat meeting and capable of supporting aquatic life designated uses $[25,26]$. Obvious point source impacts, that is, field tiles, wastewater treatment plants, or confined feeding operations, occurring along the stream reach are noted for further investigation in the event that site impairment was observed.

Land use was calculated using catchment scale land use obtained from Purdue University's Watershed Delineation Map Interface, which utilizes the United States Geological Surveys' 30-meter resolution National Land Cover Database based on 1992 Landsat imagery. This tool delineates the sitespecific catchment and the number of acres associated with each land-use practice.

Grab water samples for laboratory analyses were collected in $1,000 \mathrm{~mL}$ certified contaminant-free sample bottles from the visual centroid of flow $[4,7,8]$. Sampling devices were cleaned and then rinsed with deionized water after each use and were placed in clean storage for transport between sites. Once water samples were taken and preservatives added $\left(2 \mathrm{~mL}\right.$ sulfuric acid $\left(\mathrm{H}_{2} \mathrm{SO}_{4}\right)$ for nutrients and $5 \mathrm{~mL}$ nitric acid $\left(\mathrm{HNO}_{3}\right)$ for metals), the exteriors of all sample bottles were rinsed with deionized water and placed in ice filled coolers for transport to the State of Indiana Department of Environmental Management laboratory. Duplicate water samples, matrix spike (MS)/matrix spike duplicates (MSDs), and field blanks were collected at a rate of 1 for every 20 samples or 1 sample per week when less than 20 samples were taken. Test methods, reporting limits, and water quality criteria follow standard EPA methods for surface water analyses. Field parameter measurements were taken with a YSI multiparameter water-chemistry analysis unit. Parameters included $\mathrm{pH}$, temperature $\left({ }^{\circ} \mathrm{C}\right.$ ), specific conductance (micro$\mathrm{S})$, turbidity (NTU), and dissolved oxygen ( $\mathrm{ppm}$ ).

2.5. Statistical Data Analysis. The biological response gradient is based on the stressor identification methods outlined in Morris et al. [4] and further refined in Morris et al. [8]. Standardized (converted site data to a mean of " 0 " and standard deviation of "1") assemblage data were analyzed with cluster analysis using Euclidean Distance Similarity Matrix based on Ward's Method to create a two-dimensional dendrogram of the similarity matrix $[27,28]$.

A basic assumption of the Morris et al. [4] model is that biological assemblage structure is the result of external driving forces. These forces are identifiable and these groupings can be used to evaluate physical and chemical variables relative to the identified groupings $[4,7,8]$. It is expected that the interpretive power of the assemblage data increases as the cluster analysis segregates data into finer resolution groupings; however, at some point groupings cease to be driven by definable stressors and instead become a reflection of increased noise. We use the index of biotic integrity (IBI) scores for fish assemblage [29], which is a multimetric index of fish assemblage condition, and the Shannon Weiner $\left(\mathrm{H}^{\prime}\right)$ scores [30] for both crayfish and macroinvertebrate assemblages as our calibration tool to determine the point where noise drives the clustering patterns. Summary statistics were generated for each cluster grouping and used to rearrange clusters in order of increasing condition or species diversity, in ascending order, relative to mean IBI [29] or Shannon Weiner $\left(\mathrm{H}^{\prime}\right)$ score [30]. The lowest tier that elicited a clear increasing dose response that followed an increasing intuitive biological condition or species diversity response was selected for continued analysis $[4,7,8]$.

Cluster models were evaluated at varying linkage levels using reach specific physical, chemical, and biological data $[4,7,8]$. Chemical concentrations below the detection limit of the analytical method were maintained in the analysis and given a value consistent with $1 / 2$ of the detection limit. Clusters were treated as grouping variables and tested for significance using the Kruskal-Wallis ANOVA by Ranks test [28]. All variables demonstrating a significant relationship $(\alpha<0.05)$ with the biological condition gradient were retained as stressors explaining biological condition.

The stressor identification methodology $[4,7,8]$ identifies a series of variables that collectively explain the variability in biological assemblage structure. Since the model identifies a degree of connectivity between each stressor and biological response, a factor analysis was used to determine each stressors relative contribution to the explanation of cumulative variance. Significant stressors were normalized, standardized, and evaluated for strong correlation using Pearson's correlation [28]. If the correlation coefficient exceeded an $r$ of 0.80 , then only one variable was chosen to represent the cumulative relationship $[4,7,8]$. Factor analysis was run using the Principal Components method and interpreted using a Varimax raw rotation.

\section{Results}

The species richness included 37 fish species (Supplemental Materials Table A, available online at http://dx.doi.org/ 10.1155/2014/893795), 165 macroinvertebrate taxa (Supplemental Materials Table B), and 7 crayfish species (Supplemental Materials Table C). Analysis of assemblage structure based on cluster analysis showed that each assemblage group explained variance in the data differently (i.e., Figure 2(a) fish, Figure 2(b) macroinvertebrates, and Figure 2(c) crayfish). Each assemblage structure was explained by increasing index of biotic integrity scores for fish or increasing Shannon Weiner species diversity $\left(\mathrm{H}^{\prime}\right)$ for macroinvertebrates and crayfish (Figure 3). Information content was optimized using the Wards method which focuses on maximizing groupings. These groupings were then arranged to highlight an increasing dose response relationship. Fish assemblage structure was explained with six clusters (Figure 3(a)); macroinvertebrate assemblage structure was explained with five clusters (Figure 3(b)), while crayfish assemblage structure was explained with three clusters (Figure 3(c)). These tier groupings are externally driven by the biological assemblage structure, which can be identified as physical and chemical stress on the respective assemblage [4]. 


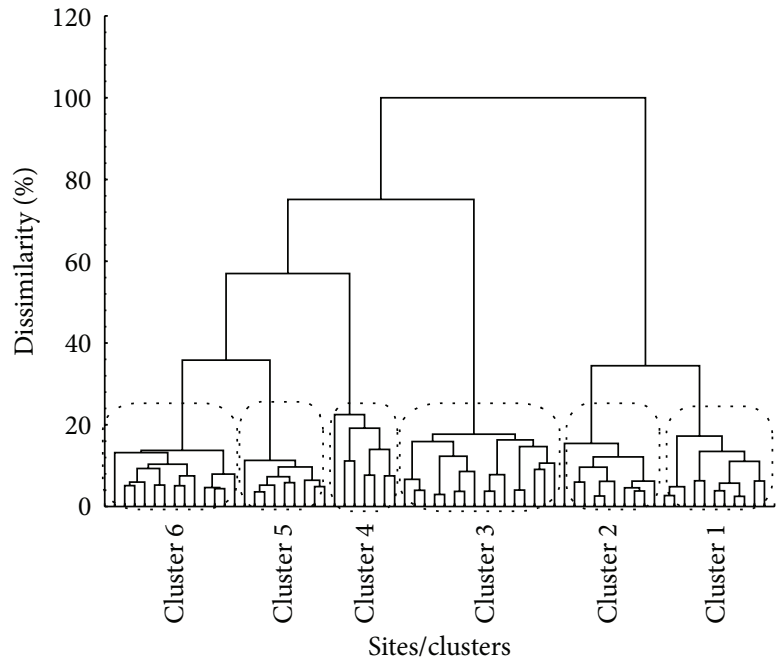

(a)

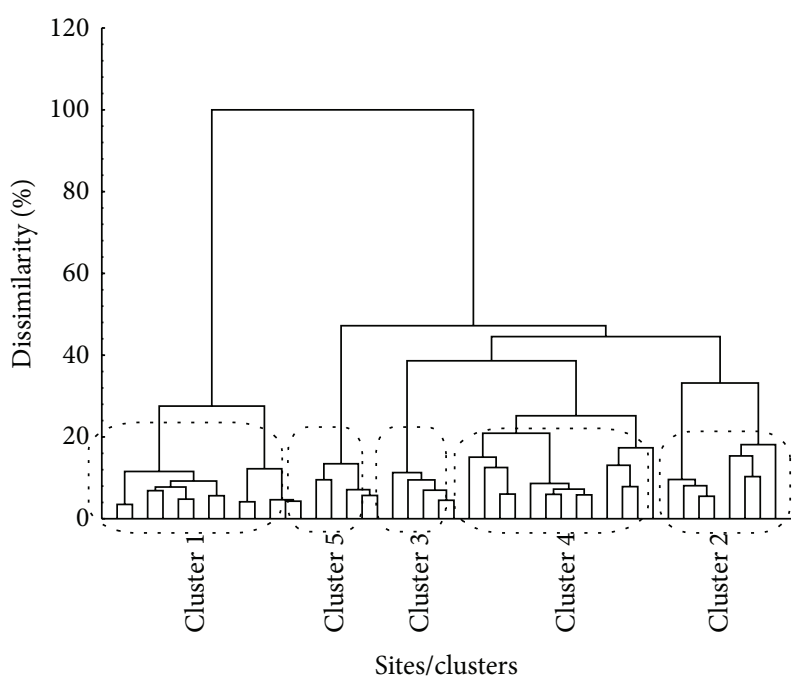

(b)

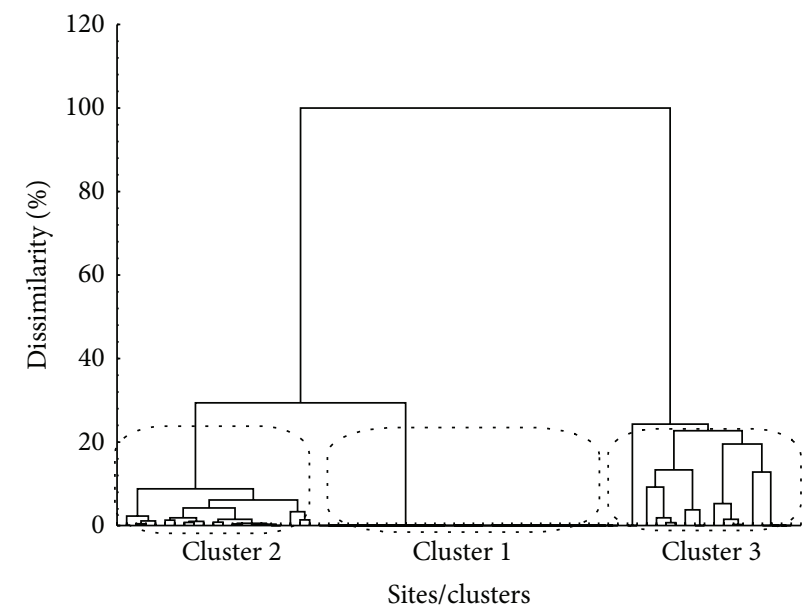

(c)

FIgURE 2: Dendrograms showing the relative similarity of assemblage data collected in the Big Oaks National Wildlife Refuge watersheds during August 2006. Boxes show the clustering at each of the similarity tiers evaluated with ANOVA. (a) Fish, (b) macroinvertebrate, and (c) crayfish assemblages.

\subsection{Physical Habitat, Water Quality, and Contaminant} Response Patterns. Habitat analysis using the QHEI showed that scores ranged from 25 to 85 (average $61.36 \pm 10.08$ ). The QHEI scores reflected habitat quality that is meeting designated uses for aquatic life $[25,26]$. Sites scoring less than 34 QHEI points are considered not meeting designated uses for aquatic life, while scores above 66 QHEI points are considered reference quality [26]. The substrate score, instream cover, riffle-run score, and channel score were the primary factors contributing to declining QHEI scores in the Big Oaks National Wildlife Refuge study area (Tables 1, 2, and 3).

We selected $75 \%$ similarity, determined through cluster analysis using Ward's method $[4,7,8]$ as a benchmark for defining assemblage structure clustering (Figure 2). These clusters were used for stressor response measurement. Summary statistics by assemblage for water chemistry results are found in Tables 1-3. Project specific summary statistics and range of scale values for water quality results are presented in Supplemental Materials Table D. In general, the lowest biological integrity and species richness clusters had the highest concentrations of contaminants (Tables 1-3). Several contaminants, such as nitrogen and phosphorus, showed differential distribution with higher concentrations for fish. Barium, sulfate, and manganese showed the highest concentrations in clusters 2 for macroinvertebrates, and fluoride and lead showed the higher concentrations in cluster 3.

3.1.1. Water Quality and Contaminant Response. KruskalWallis ANOVA by Ranks tests was significant showing that ten chemical measures were significantly predictive of the fish assemblage structure (Table 4). Predictive variables chloride, fluoride, sodium, total solids, nitrite + nitrate, and phosphorus demonstrated similar response patterns and are associated with both wastewater effluent and agricultural practice, suggesting an assemblage response signature to 


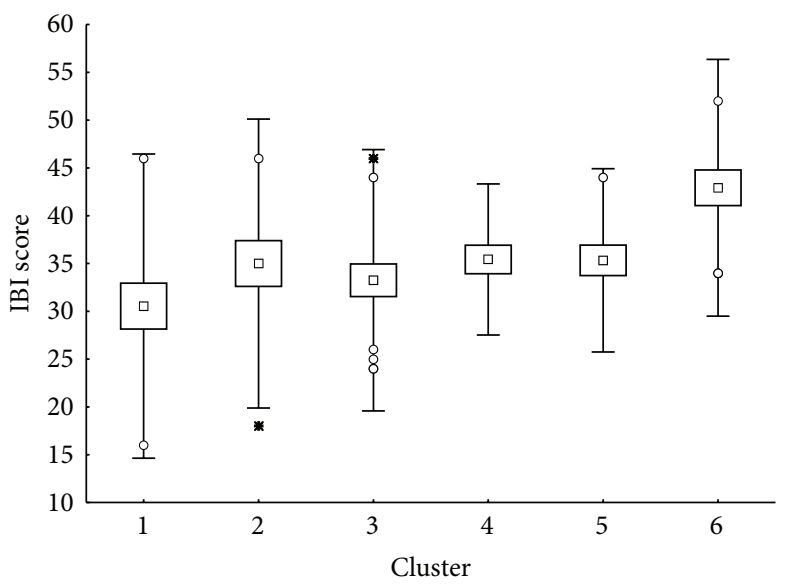

(a)

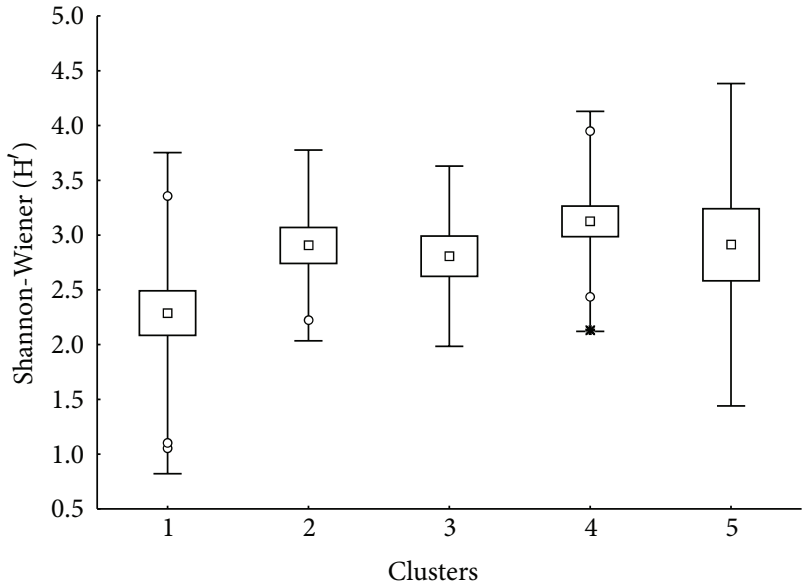

(b)

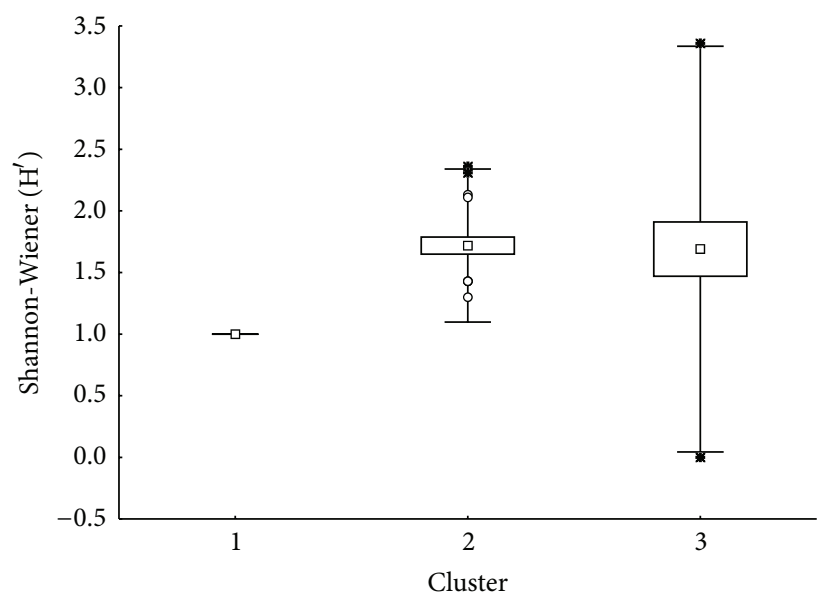

(c)

FIGURE 3: Box-and-whisker plots showing biological assemblage responses for Shannon Weiner $\left(\mathrm{H}^{\prime}\right)$ for (a) fish (b) macroinvertebrates and (c) crayfish assemblages based on the biologic response gradient developed from the Big Oaks National Wildlife Refuge watersheds during August 2006.

these practices. Similarly, fish assemblage structure was significantly predicted by the presence of arsenic, calcium, hardness, and conductivity which are common groundwater constituents suggesting a significant ground/surface water interaction response signature as well (Table 4).

Macroinvertebrate assemblages responded to fewer chemical stressors than fish but exhibit similar response patterns. Macroinvertebrate assemblages were significantly explained by both groundwater and wastewater effluent signatures. Common waste water constituents, that is, fluoride, lead, and sulfate, were predictive of macroinvertebrate structure as were groundwater constituents of $\mathrm{pH}$, manganese, and barium. While both fish and macroinvertebrates seemed to react to wastewater and groundwater stimulus, macroinvertebrates responded to only half as many wastewater components suggesting that fish are more responsive to wastewater disturbance (Tables 4 and 5).

In contrast to both fish and macroinvertebrates, crayfish assemblages did not exhibit any relationship with groundwater stimulus; rather, crayfish responded solely to wastewater and agriculture stimulus demonstrating a nutrient dominated response signature. Crayfish assemblages were significantly predicted by nitrogen, phosphorus, chloride, and total solids, all known constituents of wastewater effluent or treatment (Table 4). Crayfish reached higher relative abundance in areas with increased nutrients (i.e., nitrogen and phosphorus), while the highest and the lowest species richness were seen in areas with the lowest nutrient concentrations.

3.1.2. Habitat Response. Fish assemblage structure responded to the most habitat parameters (7) of the three organism groups followed by macroinvertebrates (4) habitat parameters and crayfish (2) habitat attributes (Table 4). Fish assemblage structure showed a significant response to QHEI score, substrate score, instream cover, riparian score, pool-glide score, riffle-run score, and gradient (Table 4).

Macroinvertebrates also responded to QHEI score, rifflerun score, and gradient, but they also responded to channel score (Table 4). These habitat attributes are probably autocorrelated since channel modifications affect the presence of riffles, which is mediated by gradient and affects the total 
TABLE 1: Summary statistics for 22 chemistry (concentration/ppm), habitat, and land use variables by fish grouping cluster (see Figure 2(a)) in watersheds of the Big Oaks National Wildlife Refuge.

\begin{tabular}{|c|c|c|c|c|c|}
\hline Variable & $N$ & Mean & Min & Max & SD \\
\hline Cluster 1 & - & - & - & - & - \\
\hline Arsenic & 11 & 2.35 & 0.2 & 8.15 & 2.64 \\
\hline Calcium & 11 & 104.45 & 75 & 145 & 21.95 \\
\hline Chloride & 11 & 12.51 & 0.05 & 44 & 13.37 \\
\hline Fluoride & 11 & 0.14 & 0.05 & 0.3 & 0.08 \\
\hline Hardness & 11 & 153.45 & 118 & 215 & 31.27 \\
\hline Nitrogen & 11 & 0.4 & 0.01 & 2.8 & 0.84 \\
\hline Total phosphorus & 11 & 0.11 & 0.03 & 0.41 & 0.11 \\
\hline Sodium & 11 & 6.98 & 2.27 & 20.1 & 4.87 \\
\hline Total solids & 11 & 300.73 & 180 & 1010 & 240.92 \\
\hline Conductivity & 11 & 493.73 & 21 & 2600 & 706.16 \\
\hline QHEI & 11 & 55.77 & 25 & 69.5 & 11.23 \\
\hline QHEI-substrate score & 11 & 11.41 & 1 & 15 & 3.77 \\
\hline QHEI-instream cover score & 11 & 6.64 & 2 & 11 & 3.38 \\
\hline QHEI-riparian score & 11 & 8.82 & 4 & 10 & 1.82 \\
\hline QHEI_pool/glide score & 11 & 4.64 & 3 & 8 & 1.29 \\
\hline QHEI_riffle/run score & 11 & 3.73 & 0 & 5 & 1.62 \\
\hline QHEI-gradient score & 11 & 4.55 & 2 & 8 & 1.81 \\
\hline Water land use & 11 & 1.88 & 0 & 14.62 & 4.38 \\
\hline Agricultural land use & 11 & 26.84 & 0 & 53.07 & 22.26 \\
\hline Grass/pasture land use & 11 & 27.01 & 0.13 & 59.75 & 22.72 \\
\hline Forest land use & 11 & 39.91 & 0 & 96.47 & 36.5 \\
\hline Industrial land use & 11 & 3.92 & 0 & 13.19 & 5.7 \\
\hline Cluster 2 & - & - & - & - & - \\
\hline Arsenic & 10 & 0.47 & 0.2 & 1.73 & 0.58 \\
\hline Calcium & 10 & 81.3 & 28 & 156 & 36.95 \\
\hline Chloride & 10 & 3.85 & 0.05 & 12 & 5.1 \\
\hline Fluoride & 10 & 0.09 & 0.05 & 0.1 & 0.02 \\
\hline Hardness & 10 & 113.2 & 38 & 235 & 54.49 \\
\hline Nitrogen & 10 & 0.08 & 0.01 & 0.5 & 0.16 \\
\hline Total phosphorus & 10 & 0.05 & 0.03 & 0.13 & 0.04 \\
\hline Sodium & 10 & 4.99 & 2.16 & 16.9 & 4.52 \\
\hline Total solids & 10 & 163.6 & 90 & 300 & 55.65 \\
\hline Conductivity & 10 & 237.09 & 87.2 & 477 & 105.49 \\
\hline QHEI & 10 & 60.85 & 50.5 & 79 & 9.51 \\
\hline QHEI_substrate score & 10 & 13.25 & 10.5 & 17 & 2.14 \\
\hline QHEI-instream cover score & 10 & 6.5 & 2 & 12 & 3.44 \\
\hline QHEI-riparian score & 10 & 9.85 & 8.5 & 10 & 0.47 \\
\hline QHEI_pool/glide score & 10 & 5 & 4 & 7 & 1.15 \\
\hline QHEI_riffle/run score & 10 & 4.4 & 2 & 7 & 1.51 \\
\hline QHEI_gradient score & 10 & 5 & 4 & 10 & 2.16 \\
\hline Water land use & 10 & 7.99 & 0.61 & 19.34 & 5.82 \\
\hline Agricultural land use & 10 & 6.8 & 0.22 & 20.1 & 7.56 \\
\hline Grass/pasture land use & 10 & 11.7 & 0.05 & 34.57 & 13.84 \\
\hline Forest land use & 10 & 63.09 & 40.46 & 81.59 & 14.74 \\
\hline Industrial land use & 10 & 9.01 & 0 & 17.96 & 6.12 \\
\hline Cluster 3 & - & - & - & - & - \\
\hline Arsenic & 16 & 1.79 & 0.2 & 2.86 & 0.56 \\
\hline Calcium & 16 & 119.56 & 85 & 154 & 22.47 \\
\hline
\end{tabular}


TABle 1: Continued.

\begin{tabular}{|c|c|c|c|c|c|}
\hline Variable & $N$ & Mean & Min & Max & $\mathrm{SD}$ \\
\hline Chloride & 16 & 30.63 & 12 & 124 & 26.98 \\
\hline Fluoride & 16 & 0.18 & 0.1 & 0.5 & 0.11 \\
\hline Hardness & 16 & 166.38 & 108 & 226 & 37.37 \\
\hline Nitrogen & 16 & 2.42 & 0.01 & 24 & 5.96 \\
\hline Total phosphorus & 16 & 0.24 & 0.04 & 1.82 & 0.44 \\
\hline Sodium & 16 & 15.75 & 5.34 & 71.3 & 16.35 \\
\hline Total solids & 16 & 279.5 & 192 & 575 & 97 \\
\hline Conductivity & 16 & 438.25 & 313 & 812 & 128.76 \\
\hline QHEI & 16 & 57.78 & 38 & 67.5 & 7.91 \\
\hline QHEI-substrate score & 16 & 13.53 & 11 & 17 & 1.94 \\
\hline QHEI-instream cover score & 16 & 6.25 & 2 & 12 & 2.27 \\
\hline QHEI-riparian score & 16 & 7.28 & 4 & 10 & 2.18 \\
\hline QHEI-pool/glide score & 16 & 5.94 & 4 & 9 & 1.53 \\
\hline QHEI_riffle/run score & 16 & 4.03 & 1 & 5.5 & 1.41 \\
\hline QHEI_gradient score & 16 & 6 & 4 & 10 & 2.42 \\
\hline Water land use & 16 & 1.04 & 0.17 & 5.67 & 1.27 \\
\hline Agricultural land use & 16 & 41.83 & 7.88 & 54.27 & 12.18 \\
\hline Grass/pasture land use & 16 & 37.71 & 25.43 & 57.81 & 10.19 \\
\hline Forest land use & 16 & 17.88 & 9.35 & 44.6 & 8.23 \\
\hline Industrial land use & 16 & 0.49 & 0 & 7.9 & 1.97 \\
\hline Cluster 4 & - & - & - & - & - \\
\hline Arsenic & 7 & 1.86 & 1.34 & 3.67 & 0.81 \\
\hline Calcium & 7 & 90 & 22 & 117 & 32.14 \\
\hline Chloride & 7 & 7.17 & 0.05 & 20 & 9.2 \\
\hline Fluoride & 7 & 0.06 & 0.05 & 0.1 & 0.02 \\
\hline Hardness & 7 & 128.14 & 35 & 178 & 47.11 \\
\hline Nitrogen & 7 & 0.04 & 0.01 & 0.2 & 0.07 \\
\hline Total phosphorus & 7 & 0.07 & 0.03 & 0.1 & 0.02 \\
\hline Sodium & 7 & 5.11 & 3.04 & 8.38 & 2.05 \\
\hline Total solids & 7 & 195.57 & 88 & 264 & 59.26 \\
\hline Conductivity & 7 & 266.84 & 72.9 & 370 & 99.88 \\
\hline QHEI & 7 & 59 & 41.5 & 65.5 & 8.79 \\
\hline QHEI-substrate score & 7 & 12.5 & 11 & 15 & 1.71 \\
\hline QHEI-instream cover score & 7 & 10.57 & 7 & 15 & 2.94 \\
\hline QHEI-riparian score & 7 & 9 & 3 & 10 & 2.65 \\
\hline QHEI_pool/glide score & 7 & 6.43 & 5 & 7 & 0.98 \\
\hline QHEI-riffle/run score & 7 & 2.57 & 0 & 5 & 1.9 \\
\hline QHEI_gradient score & 7 & 3.43 & 2 & 4 & 0.98 \\
\hline Water land use & 7 & 4.79 & 0.15 & 14.31 & 5.35 \\
\hline Agricultural land use & 7 & 18.05 & 0 & 49.9 & 22.16 \\
\hline Grass/pasture land use & 7 & 17.63 & 0 & 59.79 & 23.65 \\
\hline Forest land use & 7 & 51.56 & 6.5 & 81.31 & 33.88 \\
\hline Industrial land use & 7 & 7.45 & 0 & 22.43 & 8.49 \\
\hline Cluster 5 & - & - & - & - & - \\
\hline Arsenic & 9 & 1.45 & 0.2 & 2.1 & 0.52 \\
\hline Calcium & 9 & 111.78 & 77 & 178 & 27.79 \\
\hline Chloride & 9 & 6.67 & 0.05 & 12 & 4.33 \\
\hline Fluoride & 9 & 0.11 & 0.05 & 0.2 & 0.06 \\
\hline Hardness & 9 & 141.33 & 106 & 245 & 43.77 \\
\hline Nitrogen & 9 & 0.41 & 0.01 & 1.2 & 0.36 \\
\hline
\end{tabular}


TABle 1: Continued.

\begin{tabular}{|c|c|c|c|c|c|}
\hline Variable & $N$ & Mean & Min & Max & SD \\
\hline Total phosphorus & 9 & 0.1 & 0.03 & 0.16 & 0.05 \\
\hline Sodium & 9 & 4.9 & 2.34 & 8.67 & 1.85 \\
\hline Total solids & 9 & 204.56 & 155 & 291 & 41.22 \\
\hline Conductivity & 9 & 266.08 & 57.7 & 431 & 100.42 \\
\hline QHEI & 9 & 63.72 & 45 & 74.5 & 9.61 \\
\hline QHEI-substrate score & 9 & 12.78 & 9 & 16 & 2.12 \\
\hline QHEI-instream cover score & 9 & 7 & 5 & 10 & 1.87 \\
\hline QHEI-riparian score & 9 & 9.89 & 9 & 10 & 0.33 \\
\hline QHEI_pool/glide score & 9 & 6.67 & 5 & 9 & 1.32 \\
\hline QHEI-riffle/run score & 9 & 4.67 & 0 & 7 & 2.22 \\
\hline QHEI-gradient score & 9 & 6.22 & 2 & 10 & 2.91 \\
\hline Water land use & 9 & 2.12 & 0.11 & 5.8 & 2.33 \\
\hline Agricultural land use & 9 & 18.17 & 0 & 36.65 & 14.18 \\
\hline Grass/pasture land use & 9 & 21.34 & 0 & 47.85 & 16.31 \\
\hline Forest land use & 9 & 53.63 & 24.15 & 96.48 & 26.75 \\
\hline Industrial land use & 9 & 3.99 & 0 & 17.65 & 5.82 \\
\hline Cluster 6 & - & - & - & - & - \\
\hline Arsenic & 13 & 1.54 & 0.2 & 2.41 & 0.66 \\
\hline Calcium & 13 & 116.69 & 63 & 180 & 37.86 \\
\hline Chloride & 13 & 10.64 & 0.05 & 40 & 10.06 \\
\hline Fluoride & 13 & 0.12 & 0.05 & 0.3 & 0.09 \\
\hline Hardness & 13 & 150.85 & 88 & 220 & 48.12 \\
\hline Nitrogen & 13 & 0.69 & 0.01 & 5 & 1.32 \\
\hline Total phosphorus & 13 & 0.11 & 0.03 & 0.37 & 0.09 \\
\hline Sodium & 13 & 6.48 & 2.85 & 22.8 & 5.18 \\
\hline Total solids & 13 & 218.38 & 129 & 366 & 62 \\
\hline Conductivity & 13 & 335.54 & 195 & 562 & 104.56 \\
\hline QHEI & 13 & 70.54 & 54 & 85 & 7.39 \\
\hline QHEI_substrate score & 13 & 14.85 & 12 & 18 & 1.65 \\
\hline QHEI-instream cover score & 13 & 8.54 & 5 & 14 & 2.67 \\
\hline QHEI-riparian score & 13 & 9.27 & 6 & 10 & 1.2 \\
\hline QHEI-pool/glide score & 13 & 7 & 5 & 12 & 2.2 \\
\hline QHEI-riffle/run score & 13 & 5.77 & 3 & 7 & 1.49 \\
\hline QHEI-gradient score & 13 & 7.54 & 4 & 10 & 2.18 \\
\hline Water land use & 13 & 1.88 & 0.37 & 6.25 & 2.03 \\
\hline Agricultural land use & 13 & 24.31 & 1.13 & 50.97 & 14 \\
\hline Grass/pasture land use & 13 & 27.24 & 5.86 & 53.14 & 16.76 \\
\hline Forest land use & 13 & 41.99 & 17.11 & 83.95 & 20.59 \\
\hline Industrial land use & 13 & 3.54 & 0 & 20.11 & 5.76 \\
\hline
\end{tabular}

habitat quality score. While both fish and macroinvertebrate assemblages responded to habitat quality (QHEI), specific response signatures differed by habitat partition and component.

Of the three assemblages, crayfish responded to the fewest habitat variables, significantly responding to only riparian score and the pool-glide score (Table 4). Crayfish preference for slower moving pool/glide habitats in conjunction with the presence of an intact riparian corridor that potentially limits the growth of algae may explain this response. Additionally, lack of algal growth may also limit the invasion of rusty crayfish, which can numerically dominate a system excluding other native species.

3.1.3. Land Use Response. Fish assemblage structure showed the most significant relationship with land use (Table 4) showing a significant response to agriculture, grass-pasture, forest, industrial, and water land uses. Of the three organism groups studied, fish would probably have the greatest dependence on water permanence since desiccation would restrict migration and recolonization following drought conditions. Macroinvertebrate structure was significant for water land 
TABLE 2: Summary statistics for eight chemistry (concentration/ppm), habitat, and land use variables by macroinvertebrate grouping cluster (see Figure 2(b)) in watersheds of the Big Oaks National Wildlife Refuge.

\begin{tabular}{|c|c|c|c|c|c|}
\hline Variable & $N$ & Mean & Min & $\operatorname{Max}$ & SD \\
\hline Cluster 1 & - & - & - & - & - \\
\hline Barium & 13 & 52.46 & 30.5 & 81.9 & 12.93 \\
\hline Fluoride & 13 & 0.12 & 0.05 & 0.2 & 0.06 \\
\hline Lead & 13 & 0.19 & 0.1 & 1.31 & 0.34 \\
\hline Manganese & 13 & 124.52 & 39.7 & 275 & 71.42 \\
\hline Sulfate & 13 & 13.99 & 9.1 & 23 & 4.07 \\
\hline $\mathrm{pH}$ & 13 & 8.13 & 7.44 & 9.5 & 0.59 \\
\hline QHEI score & 13 & 58.23 & 50.5 & 70.5 & 5.23 \\
\hline Water land use & 13 & 3.53 & 0.06 & 14.62 & 5.01 \\
\hline Cluster 2 & - & - & - & - & - \\
\hline Barium & 5 & 53.3 & 34.8 & 67 & 11.63 \\
\hline Fluoride & 5 & 0.07 & 0.05 & 0.1 & 0.03 \\
\hline Lead & 5 & 0.1 & 0.1 & 0.1 & 0 \\
\hline Manganese & 5 & 67.12 & 31.7 & 130 & 41.7 \\
\hline Sulfate & 5 & 15.6 & 12 & 20 & 3.29 \\
\hline $\mathrm{pH}$ & 5 & 8.31 & 7.45 & 8.69 & 0.51 \\
\hline QHEI score & 5 & 64.9 & 62.5 & 67.5 & 2.38 \\
\hline Water land use & 5 & 2.99 & 0.41 & 6.25 & 2.79 \\
\hline Cluster 3 & - & - & - & - & - \\
\hline Barium & 5 & 79.6 & 56.7 & 124 & 27.59 \\
\hline Fluoride & 5 & 0.19 & 0.05 & 0.3 & 0.09 \\
\hline Lead & 5 & 1.27 & 0.1 & 3.13 & 1.29 \\
\hline Manganese & 5 & 672 & 52 & 2500 & 1038.09 \\
\hline Sulfate & 5 & 9.28 & 7.2 & 11 & 1.74 \\
\hline $\mathrm{pH}$ & 5 & 7.67 & 7.14 & 7.9 & 0.31 \\
\hline QHEI score & 5 & 56.6 & 25 & 67 & 17.81 \\
\hline Water land use & 5 & 0.23 & 0 & 0.5 & 0.24 \\
\hline Cluster 4 & - & - & - & - & - \\
\hline Barium & 13 & 55.74 & 31.9 & 107 & 18.03 \\
\hline Fluoride & 13 & 0.07 & 0.05 & 0.1 & 0.03 \\
\hline Lead & 13 & 0.1 & 0.1 & 0.1 & 0 \\
\hline Manganese & 13 & 104.31 & 25.7 & 265 & 63.09 \\
\hline Sulfate & 13 & 11.69 & 5.2 & 18 & 3.98 \\
\hline $\mathrm{pH}$ & 13 & 8.26 & 7.66 & 9.19 & 0.45 \\
\hline QHEI score & 13 & 68.31 & 55 & 79 & 9.06 \\
\hline Water land use & 13 & 2.84 & 0.48 & 5.8 & 2.07 \\
\hline Cluster 5 & - & - & - & - & - \\
\hline Barium & 7 & 90.43 & 47.2 & 158 & 43.26 \\
\hline Fluoride & 7 & 0.14 & 0.05 & 0.2 & 0.07 \\
\hline Lead & 7 & 0.67 & 0.1 & 2.96 & 1.1 \\
\hline Manganese & 7 & 1352.21 & 99.5 & 6360 & 2322.74 \\
\hline Sulfate & 7 & 22.8 & 6.9 & 45 & 14.67 \\
\hline $\mathrm{pH}$ & 7 & 7.68 & 7.21 & 8.43 & 0.39 \\
\hline QHEI score & 7 & 51.93 & 38 & 64 & 9.75 \\
\hline Water land use & 7 & 0.57 & 0.13 & 1.23 & 0.41 \\
\hline
\end{tabular}

use (Table 4), while crayfish showed a significant response to commercial land use (Table 4).
TABLE 3: Summary statistics for seven chemistry (concentration/ppm), habitat, and land use variables by crayfish grouping cluster (see Figure 2(c)) in watersheds of the Big Oaks National Wildlife Refuge.

\begin{tabular}{lccccc}
\hline Variable & $N$ & Mean & Min & Max & SD \\
\hline Cluster 1 & - & - & - & - & - \\
Chloride & 32 & 9.9 & 0.05 & 44 & 11.14 \\
Nitrogen & 32 & 0.24 & 0.01 & 2.8 & 0.51 \\
Total phosphorus & 32 & 0.07 & 0.03 & 0.19 & 0.05 \\
Total solids & 32 & 202.94 & 90 & 301 & 47.7 \\
QHEI-riparian score & 32 & 9.3 & 4 & 10 & 1.49 \\
QHEI-pool/glide score & 32 & 5.53 & 3 & 9 & 1.46 \\
Commercial land use & 32 & 0.62 & 0 & 3.83 & 1.07 \\
Cluster 2 & - & - & - & - & - \\
Chloride & 20 & 21.91 & 0.05 & 124 & 26.61 \\
Nitrogen & 20 & 2.18 & 0.01 & 24 & 5.41 \\
Total phosphorus & 20 & 0.23 & 0.03 & 1.82 & 0.4 \\
Total solids & 20 & 299.1 & 105 & 1010 & 197.87 \\
QHEI-riparian score & 20 & 8.08 & 3 & 10 & 2.27 \\
QHEI-pool/glide score & 20 & 5.65 & 4 & 8 & 1.27 \\
Commercial land use & 20 & 0.06 & 0 & 0.31 & 0.1 \\
Cluster 3 & - & - & - & - & - \\
Chloride & 14 & 11.4 & 0.05 & 46 & 12.59 \\
Nitrogen & 14 & 0.4 & 0.01 & 1.2 & 0.39 \\
Total phosphorus & 14 & 0.1 & 0.05 & 0.16 & 0.04 \\
Total solids & 14 & 213.5 & 88 & 333 & 60.27 \\
QHEI-riparian score & 14 & 8.96 & 4 & 10 & 1.82 \\
QHEI-pool/glide score & 14 & 7.29 & 4 & 12 & 2.16 \\
Commercial land use & 14 & 1.14 & 0 & 7.78 & 2.4 \\
\hline
\end{tabular}

Fish assemblage structure showed declining dose response patterns for water, agriculture, and industrial land uses (Table 4). Macroinvertebrate assemblage structure was most variable with water land use (Table 4), while crayfish assemblage structure showed the highest species richness in commercial land uses (Table 4).

3.2. Factor Analysis. Further assessment of patterns and relationships between contaminants identified as highly predictive and those significantly correlated with causal patterns in assemblage structure changes was completed using factor analysis. Factor analysis is a statistical method used to explain variability among observed variables in terms of fewer unobserved variables called factors $[27,28]$. The observed variables are modeled as linear combinations of the factors, plus "error" terms. The information gained about the interdependencies can be used to reduce the set of variables in a dataset $[4,7,8]$.

Fish assemblage structure was explained by four factors, accounting for $69 \%$ of the cumulative variance (Table 5). This is the proper notation for Factor analysis. Three variables representing groundwater (arsenic), wastewater (phosphorus), and agricultural influences (phosphorus and agriculture land use) explaining $26 \%$ of the cumulative variance. Factor 2 loaded significantly on two habitat measures, QHEI score and gradient score, and explained another $23 \%$ of the cumulative 
TABLE 4: List of 30 physical and chemical variables significantly predictive $(\alpha=0.05)$ of the fish, macroinvertebrate, and crayfish assemblage biologic gradient using the Kruskal-Wallis ANOVA by ranks test in watersheds of the Big Oaks National Wildlife Refuge.

\begin{tabular}{|c|c|c|c|}
\hline Variable & $\begin{array}{c}\text { Fish } \\
P \text {-value }\end{array}$ & $\begin{array}{c}\text { Macroinvertebrate } \\
P \text {-value }\end{array}$ & $\begin{array}{l}\text { Crayfish } \\
P \text {-value }\end{array}$ \\
\hline \multicolumn{4}{|l|}{ General } \\
\hline $\begin{array}{l}\text { Water } \\
\text { Temperature }\end{array}$ & 0.0036 & & \\
\hline \multicolumn{4}{|l|}{ Chemical } \\
\hline Arsenic & 0.0070 & & \\
\hline Barium & & 0.0169 & \\
\hline Calcium & 0.0422 & & \\
\hline Chloride & 0.0000 & & 0.0347 \\
\hline Fluoride & 0.0109 & 0.0140 & \\
\hline Lead & & 0.0103 & \\
\hline Manganese & & 0.0075 & \\
\hline Sulfate & & 0.0477 & \\
\hline Hardness & 0.0524 & & \\
\hline Nitrogen & 0.0013 & & 0.0383 \\
\hline Phosphorus & 0.0195 & & 0.0280 \\
\hline Sodium & 0.0003 & & \\
\hline $\mathrm{pH}$ & & 0.0455 & \\
\hline Total solids & 0.0010 & & 0.0332 \\
\hline Conductivity & 0.0003 & & \\
\hline \multicolumn{4}{|l|}{ Habitat } \\
\hline QHEI score & 0.0022 & 0.0055 & \\
\hline Substrate score & 0.0228 & & \\
\hline $\begin{array}{l}\text { Instream cover } \\
\text { Score }\end{array}$ & 0.0354 & & \\
\hline Channel score & & 0.0016 & \\
\hline Riparian score & 0.0013 & & 0.0511 \\
\hline Pool/glide score & 0.0013 & & 0.0172 \\
\hline Riffle/run score & 0.0082 & 0.0023 & \\
\hline Gradient score & 0.0038 & 0.0346 & \\
\hline \multicolumn{4}{|l|}{ Land use } \\
\hline Water & 0.0015 & 0.0130 & \\
\hline Agriculture & 0.0003 & & \\
\hline Grass/pasture & 0.0140 & & \\
\hline Forest & 0.0003 & & \\
\hline Commercial & & & 0.0076 \\
\hline Industrial & 0.0009 & & \\
\hline
\end{tabular}

variance. Factor 3 significantly loaded on two additional variables, calcium and conductivity, both of which are associated with ground-water influence, and explained an additional $11 \%$ of the cumulative variance. Factor 4 was positively loaded on one habitat variable, in-stream cover, and explained another $9 \%$ of the variation. Within our study area, fish assemblages appear to be reacting to a variety of influences expressing distinct response signatures to groundwater, agriculture, and habitat stimulus. Cumulatively, the groundwater and agriculture driven factors (factor 1 and 3 ) accounted for $53 \%$ of the explained variance with the habitat driven factors (factors 2 and 4) explaining the remaining $47 \%$.

Macroinvertebrate assemblage structure was explained by two factors, accounting for $56 \%$ of the total variance (Table 5). The primary factor explained $38 \%$ of the variance based on a negative association between a wastewater signature (barium and lead) and a groundwater signature (manganese). The second factor was also negatively associated, but with only a single wastewater-driven variable (fluoride) explaining an additional $18 \%$ of the variance. Surprisingly, whereas $47 \%$ of the explained variance in fish assemblages could be attributed to habitat driven effect, no habitat variables were significant in explaining variation in macroinvertebrate assemblages. Within our study area macroinvertebrates appear to be most susceptible to both wastewater and groundwater stimulus.

Crayfish assemblage structure was explained by two factors that included an increasing relationship with wastewater and agricultural stimulus (chloride, nitrogen, total phosphorus, and total solids) explaining $49 \%$ of the cumulative variance (Table 5). The second factor was a positive relationship with habitat stimulus having the pool-glide score explaining an additional $17 \%$ of the variance. Of the three organismal groups, crayfish appear to exhibit the most distinct response signature having $49 \%$ of the cumulative variance being explained by a single factor dominated by a wastewater stimulus.

\section{Discussion}

The three biological assemblages elicited clear response patterns to a series of stressor variables. These physical/chemical patterns have been described in terms of broad scale factors such as wastewater treatment, agricultural, ground-water, habitat, and land use. While being intuitive, the direct association between specific source/cause still remains tenuous. However, the spatial interpretation of the significantly predictive variable by our hot spot analysis more clearly delineates these linkages.

We have defined both the wastewater and agriculture responses in terms of nutrient loads (nitrate + nitrite and phosphorus), sodium, chloride, sulfate, fluoride, total solids, and lead. Streams are often nutrient-limited, and addition of nutrients may alter stream community structure [31]. Anthropogenic disturbance of watersheds increases delivery of all forms of nitrogen from impervious surfaces [32-35], lawn-fertilizer runoff $[36,37]$, pet waste [38], construction sites [37], nutrients in precipitation [39], storm water runoff [39], leakage or overflow of wastewater sewers [40], and sewage effluent (e.g., [41]). Closer examining of the variance associated with these contaminants clearly defines contamination influences based on two patterns. (Table 4). The first, is defined by nitrate + nitrite, phosphorus, sodium, chloride sulfate, and fluoride and a second "hot spot" is defined by both total solids, lead, and to a lesser degree phosphorus and fluoride (Table 4). While all three assemblages responded to these indicator chemicals, crayfish response was the most 
TABLE 5: Results of factor analysis and explained variance observed in fish assemblage biologic structure and 16 significant chemical, habitat, and land use variables at the Big Oaks National Wildlife Refuge. Bold values are considered significant.

\begin{tabular}{|c|c|c|c|c|}
\hline Variable & Factor 1 & Factor 2 & Factor 3 & Factor 4 \\
\hline \multicolumn{5}{|l|}{ Fish assemblage } \\
\hline Arsenic & 0.783062 & -0.059175 & -0.0345 & 0.31648 \\
\hline Total phosphorus & 0.851726 & -0.017708 & 0.112252 & -0.1624 \\
\hline Agricultural land use & 0.836643 & 0.074086 & -0.01429 & 0.063424 \\
\hline QHEI score & -0.08335 & 0.929388 & 0.033943 & 0.286131 \\
\hline QHEI-gradient score & 0.251651 & 0.719733 & 0.279072 & -0.10598 \\
\hline Conductivity & -0.22656 & -0.042178 & 0.753321 & -0.04346 \\
\hline Calcium & 0.246242 & 0.219824 & 0.739182 & 0.033972 \\
\hline QHEI-instream cover score & 0.001361 & 0.146698 & 0.036967 & 0.8519 \\
\hline Cumulative explained variance & $26 \%$ & $49 \%$ & $60 \%$ & $69 \%$ \\
\hline \multicolumn{5}{|l|}{ Macroinvertebrate assemblage } \\
\hline Barium & -0.80031 & 0.002714 & & \\
\hline Lead & -0.74591 & -0.193511 & & \\
\hline Manganese & -0.91379 & 0.028777 & & \\
\hline Fluoride & -0.06312 & -0.80045 & & \\
\hline Cumulative explained variance & $38 \%$ & $56 \%$ & & \\
\hline \multicolumn{5}{|l|}{ Crayfish assemblage } \\
\hline Chloride & 0.821893 & 0.220021 & & \\
\hline Nitrogen & 0.769671 & 0.270388 & & \\
\hline Total phosphorus & 0.811131 & 0.198719 & & \\
\hline Total solids & 0.818145 & -0.221031 & & \\
\hline QHEI-pool glide score & 0.119627 & 0.909592 & & \\
\hline Cumulative explained variance & $49 \%$ & $66 \%$ & & \\
\hline
\end{tabular}

distinct having $49 \%$ of its variability (Table 5) being explained by factors directly associated with nutrient signatures.

Environmental variables among multiple spatial scales control physicochemical and biological processes in streams $[42,43]$. Variables at regional or catchment scales can affect streams directly or indirectly by constraining other environmental variables at lower scales [44-46]. Understanding the relative influence of environmental variables at catchment and local spatial scales is an important step towards improved restoration, management, and assessment of aquatic resources $[47,48]$. Patterns observed by groundwater constituents include chemical signatures such as arsenic, manganese, barium, calcium, hardness, conductivity, and $\mathrm{pH}$ (Table 5). These contaminants elicited a more spatially diffuse pattern typical of groundwater interaction within the study area. Interestingly, groundwater effect was mostly isolated to macroinvertebrates assemblages explaining $38 \%$ of the variation (Table 5).

Knowing which and how different spatial scale factors integratively affect stream communities also increases our ability to detect anthropogenic influences, identify biological response signatures to human-induced stress, and ultimately improve river health $[49,50]$. Both habitat and land use factors demonstrated a degree of spatial variation but could not be interpreted in the same context as the chemical variables. Habitat factors, while being significant, lacked the variance demonstrated by most water chemistry constituents. Weigel et al. [51] found that macroinvertebrate assemblage structure was defined along an erosional and depositional gradient. Land-use parameters in the current study demonstrate a wide degree of variation but are expressed in our analysis as finite measure of land coverage.

Although it is evident that stream fishes are influenced by both local and regional factors, the most important spatial scale differs among studies. Reports from agriculture and urban-dominated watersheds indicate that land uses are the main factors influencing stream fish communities and that local scale physical habitat plays a much less important role $[52,53]$. Studies from mixed forest-agriculture watersheds indicate that both watershed and reach scale factors are important (e.g., [45, 54]). However, there is only a limited understanding of the role of different spatial scales for relatively undisturbed watersheds [55]. Fish assemblage structure showed the most significant relationship with land use (Table 4). Fish showed a significant response to agriculture, grass-pasture, forest, industrial, and water land uses. Among all of the organismal groups studied, fish would probably have the greatest dependence on water permanence since desiccation would restrict migration and colonization following drought conditions. Macroinvertebrate structure was significant for water land use, while crayfish showed a significant response to commercial land use (Table 4). Significant habitat and land use variables were the product of a dichotomy of habitat qualities ranging from the nearly natural, undisturbed habitat on the refuge compared to the disturbed agricultural land use outside of the refuge. The variety of land uses that were significant to fish assemblage structure were a result of the differences observed between on refuge compared to off refuge land uses (Table 5). 


\section{Conclusions}

Field and toxicology studies often use multiple biological indicators, including fish and macroinvertebrates, to evaluate toxic responses from contaminants. The field linkage of these response patterns has often been less than desirable, since usually these studies are conducted in extremely disturbed environments where either an all or none effect is observed. It has long been recognized that using multiple assemblage indicators in an environmental assessment of causal effects will enable interpretation at multiple trophic levels. Differences caused from toxic effects are common but have not been satisfactorily explained. In addition, it has been almost 40 years since any interpretation of multiple assemblage information has been analyzed for patterns in field assessments. Our results show that fish, macroinvertebrate, and crayfish assemblages respond to similar broad scale stimulus; however, the specific physical/chemical constituents responsible for the stress may vary and the realized magnitude of the overall stress on the system may be expressed differentially by each organismal group. Our data suggest that varying organismal groups can respond independently and stress reflected in one assemblage may not necessarily be observed in another. Assessment of aquatic life beneficial uses should not assume that indicator assemblages will respond similarly; thus, full-, partial-, indeterminate- and nonattainment should not assume that segment scales should be similar.

\section{Conflict of Interests}

The authors declare that there is no conflict of interests regarding the publication of this paper.

\section{Acknowledgments}

This study was funded by the U.S. Fish and Wildlife Service and although this study may have been funded wholly or in part by that agency, no endorsement should be implied. Special thanks are due to S. Sobat, P. McMurray, and M. McShane for professional courtesies and field support.

\section{References}

[1] C. O. Yoder and E. T. Rankin, "The role of biological indicators in a state water quality management process," Environmental Monitoring and Assessment, vol. 51, no. 1-2, pp. 61-88, 1998.

[2] C. O. Yoder and J. E. DeShon, "Using biological response signatures within a framework of multiple indicators to assess and diagnosis causes and sources of impairment to aquatic assemblages in selected Ohio rivers and streams," in Biological Response Signatures: Indicator Patterns using Aquatic Communities, T. P. Simon, Ed., pp. 23-81, CRC Press, Boca Raton, Fla, USA, 1st edition, 2003.

[3] G. W. Suter II, S. B. Norton, and S. M. Cormier, "A methodology for inferring the causes of observed impairments in aquatic ecosystems," Environmental Toxicology and Chemistry, vol. 21, no. 6, pp. 1101-1111, 2002.

[4] C. C. Morris, T. P. Simon, and S. A. Newhouse, "A local-scale in situ approach for stressor identification of biologically impaired aquatic systems," Archives of Environmental Contamination and Toxicology, vol. 50, no. 3, pp. 325-334, 2006.

[5] United States Environmental Protection Agency, "Stressor identification guidance document," Tech. Rep. EPA/822/B-00/025, United States Environmental Protection Agency, Washington, DC, USA, 2000.

[6] T. P. Simon, Biological Response Signatures: Indicator Patterns Using Aquatic Communities, CRC Press, Boca Raton, Fla, USA, 1st edition, 2003.

[7] T. P. Simon and C. C. Morris, "Biological response signature of oil brine threats, sediment contaminants, and crayfish assemblages in an Indiana watershed, USA," Archives of Environmental Contamination and Toxicology, vol. 56, no. 1, pp. 96-110, 2009.

[8] C. C. Morris and T. P. Simon, "Evaluation of watershed stress in an urbanized landscape in southern Lake Michigan," in Watersheds: Management, Restoration and Environmental Impact, J. C. Vaughn, Ed., pp. 193-219, Nova Science, New York, NY, USA, 2011.

[9] S. B. Norton, S. M. Cormier, G. W. Suter II et al., "Determining probable causes of ecological impairment in the Little Scioto River, Ohio, USA. Part 1. Listing candidate causes and analyzing evidence," Environmental Toxicology and Chemistry, vol. 21, no. 6, pp. 1112-1124, 2002.

[10] K. W. Eagleson, D. L. Lenat, L. W. Ausley, and F. B. Winborne, "Comparison of measured instream biological responses with responses predicted using the Ceriodaphnia dubia chronic toxicity test," Environmental Toxicology and Chemistry, vol. 9, no. 8, pp. 1019-1028, 1990.

[11] K. Riva-Murray, R. W. Bode, P. J. Phillips, and G. L. Wall, "Impact source determination with biomonitoring data in New York State: concordance with environmental data," Northeastern Naturalist, vol. 9, no. 2, pp. 127-162, 2002.

[12] D. L. Stevens Jr. and A. R. Olsen, "Spatially balanced sampling of natural resources," Journal of the American Statistical Association, vol. 99, no. 465, pp. 262-278, 2004.

[13] Indiana Department of Environmental Management (IDEM), Standard Operating Procedures for Electrofishing, IDEM, Indianapolis, Indiana, USA, 1992.

[14] G. C. Becker, Fishes of Wisconsin, University of Wisconsin Press, Madison, Wis, USA, 1983.

[15] D. A. Etnier and W. C. Starnes, The Fishes of Tennessee, University of Tennessee Press, Knoxville, Tenn, USA, 1993.

[16] T. P. Simon, Fishes of Indiana: A Field Guide, Indiana University Press, Bloomington, Ind, USA, 2011.

[17] T. P. Simon, "Standard Operating Procedures for the collection and study of burrowing crayfish in Indiana. I. Methods for the collection of burrowing crayfish in streams and terrestrial habitats," Miscellaneous Papers of the Indiana Biological Survey Aquatic Research Center, vol. 2, pp. 1-16, 2004.

[18] L. M. Page, "The crayfishes and shrimps (Decapoda) of Illinois," Illinois Natural History Survey Bulletin, vol. 33, pp. 335-448, 1985.

[19] C. A. Taylor and G. A. Schuster, The Crayfishes of Kentucky, vol. 28, Illinois Natural History Survey Special Publication, 2004.

[20] T. P. Simon and P. M. Stewart, Eds., Standard Operating Procedures for Development of Watershed Indicators in REMAP: Northern Lakes and Forest Streams, U.S. Environmental Protection Agency, Chicago, Ill, USA, 1998. 
[21] R. W. Merritt and K. W. Cummins, An Introduction to the Aquatic Insects of North America, Kendall/Hunt, Dubuque, Iowa, USA, 3rd edition, 1996.

[22] B. Pekarsky, Freshwater Macroinvertebrates of Northeastern North America, Cornell University Press, Ithaca, NY, USA, 1990.

[23] J. H. Thorpe and A. P. Covich, Ecology and Classification of North American Freshwater Invertebrates, Academic Press, New York, NY, USA, 3rd edition, 2010.

[24] R. W. Pennak, Fresh-Water Invertebrates of the United States: Protozoa to Mollusca, John Wiley \& Sons, New York, NY, USA, 3rd edition, 1989.

[25] E. T. Rankin, The Qualitative Habitat Evaluation Index (QHEI): Rationale, Methods and Application, Ohio EPA, Division of Water Quality Planning and Assessment, Ecological Assessment Section, Columbus, Ohio, USA, 1989.

[26] E. T. Rankin, "The use of habitat assessments in water resource management programs," in Biological Assessment and Criteria: Tools for Water Resource Planning and Decision Making, W. S. Davis and T. P. Simon, Eds., pp. 181-208, CRC Press, Boca Raton, Fla, USA, 1995.

[27] StatSoft, STATISTICA for Windows, StatSoft, Tulsa, Okla, USA, 2002.

[28] S. Siegel and N. J. Castellan, Nonparametric Statistics for the Behavioral Sciences, McGraw-Hill, New York, NY, USA, 2nd edition, 1988 .

[29] T. P. Simon and R. L. Dufour, "Development of index of biotic integrity expectations for the ecoregions of Indiana. V. Eastern Corn Belt Plain," EPA 905/R-96/002, United States Environmental Protection Agency, Region V. Water Division. Watershed and Non-Point Source Branch, Chicago, Ill, USA, 1998.

[30] C. E. Shannon, "A mathematical theory of communication," The Bell System Technical Journal, vol. 27, pp. 379-423, 1948.

[31] W. K. Dodds and E. B. Welch, "Establishing nutrient criteria in streams," Journal of the North American Benthological Society, vol. 19, no. 1, pp. 186-196, 2000.

[32] W. G. Characklis, C. H. Ward, J. M. King, and F. L. Roe, "Rainfall quality, land use, and runoff quality," American Society of Civil Engineers, vol. 105, pp. 416-419, 1979.

[33] P. A. Soranno, S. L. Hubler, S. R. Carpenter, and R. C. Lathrop, "Phosphorus loads to surface waters: a simple model to account for spatial pattern of land use," Ecological Applications, vol. 6, no. 3, pp. 865-878, 1996.

[34] C. W. Corbett, M. Wahl, D. E. Porter, D. Edwards, and C. Moise, "Nonpoint source runoff modeling. A comparison of a forested watershed and an urban watershed on the South Carolina coast," Journal of Experimental Marine Biology and Ecology, vol. 213, no. 1, pp. 133-149, 1997.

[35] B. Albanese and G. Matlack, "Utilization of parking lots in Hattiesburg, Mississippi, USA, and impacts on local streams," Environmental Management, vol. 24, no. 2, pp. 265-271, 1998.

[36] M. H. Wahl, H. N. McKellar, and T. M. Williams, "Patterns of nutrient loading in forested and urbanized coastal streams," Journal of Experimental Marine Biology and Ecology, vol. 213, no. 1, pp. 111-131, 1997.

[37] S. R. Carpenter, N. F. Caraco, D. L. Correll, R. W. Howarth, A. N. Sharpley, and V. H. Smith, "Nonpoint pollution of surface waters with phosphorus and nitrogen," Ecological Applications, vol. 8, no. 3, pp. 559-568, 1998.
[38] A. J. Ulseth and A. E. Hershey, "Natural abundances of stable isotopes trace anthropogenic N and C in an urban stream," Journal of the North American Benthological Society, vol. 24, no. 2, pp. 270-289, 2005.

[39] S. R. Silva, P. B. Ging, R. W. Lee, J. C. Ebbert, A. J. Tesoriero, and E. L. Inkpen, "Forensic applications of nitrogen and oxygen isotopes in tracing nitrate sources in urban environments," Environmental Forensics, vol. 3, no. 2, pp. 125-130, 2002.

[40] J. Seager and R. G. Abrahams, "The impact of storm sewage discharges on the ecology of a small urban river," Water Science and Technology, vol. 22, no. 10-11, pp. 163-171, 1990.

[41] A. E. Hershey, A. J. Ulseth, and K. Fortino, "Use of stable isotopes to trace sewage effluent through a forested mid-order stream in the vicinity of Greensboro, N. C," in Proceedings of the 77th Water Environment Federation Technical Exhibition and Conference, New Orleans, La, USA, 2004.

[42] H. B. N. Hynes, The Ecology of Running Waters, Liverpool University Press, Liverpool, UK, 1970.

[43] H. B. N. Hynes, "Edgardo baldi memorial lecture. The stream and its valley," in Verhandlungen der Internationalen Vereinigung für Theoretische und Angewandte Limnologie, vol. 19, pp. $1-15,1975$.

[44] C. A. Frissell, W. J. Liss, C. E. Warren, and M. D. Hurley, "A hierarchical framework for stream habitat classification: viewing streams in a watershed context," Environmental Management, vol. 10, no. 2, pp. 199-214, 1986.

[45] J. D. Allan, D. L. Erickson, and J. Fay, "The influence of catchment land use on stream integrity across multiple spatial scales," Freshwater Biology, vol. 37, no. 1, pp. 149-161, 1997.

[46] N. L. Poff, "Landscape filters and species traits: towards mechanistic understanding and prediction in stream ecology," Journal of the North American Benthological Society, vol. 16, no. 2, pp. 391-409, 1997.

[47] C. Richards, G. E. Host, and J. W. Arthur, "Identification of predominant environmental factors structuring stream macroinvertebrate communities within a large agricultural catchment," Freshwater Biology, vol. 29, no. 2, pp. 285-294, 1993.

[48] L. B. Johnson and S. H. Gage, "Landscape approaches to the analysis of aquatic Ecosystems," Freshwater Biology, vol. 37, no. 1, pp. 113-132, 1997.

[49] R. H. Norris and M. C. Thoms, "What is river health?" Freshwater Biology, vol. 41, no. 2, pp. 197-209, 1999.

[50] B. M. Weigel, "Development of stream macroinvertebrate models that predict watershed and local stressors in Wisconsin," Journal of the North American Benthological Society, vol. 22, no. 1, pp. 123-142, 2003.

[51] B. M. Weigel, L. Wang, P. W. Rasmussen et al., "Relative influence of variables at multiple spatial scales on stream macroinvertebrates in the Northern Lakes and Forest ecoregion, USA," Freshwater Biology, vol. 48, no. 8, pp. 1440-1461, 2003.

[52] L. Wang, J. Lyons, P. Kanehl, and R. Bannerman, "Impacts of urbanization on stream habitat and fish across multiple spatial scales," Environmental Management, vol. 28, no. 2, pp. 255-266, 2001.

[53] L. Wang, J. Lyons, and P. Kanehl, "Effects of watershed best management practices on habitat and fish in Wisconsin streams," Journal of the American Water Resources Association, vol. 38, no. 3, pp. 663-680, 2002. 
[54] C. Richards, L. B. Johnson, and G. E. Host, "Landscape-scale influences on stream habitats and biota," Canadian Journal of Fisheries and Aquatic Sciences, vol. 53, no. 1, pp. 295-311, 1996.

[55] L. Wang, J. Lyons, P. Rasmussen et al., "Watershed, reach, and riparian influences on stream fish assemblages in the Northern Lakes and Forest Ecoregion, USA," Canadian Journal of Fisheries and Aquatic Sciences, vol. 60, no. 5, pp. 491-505, 2003. 

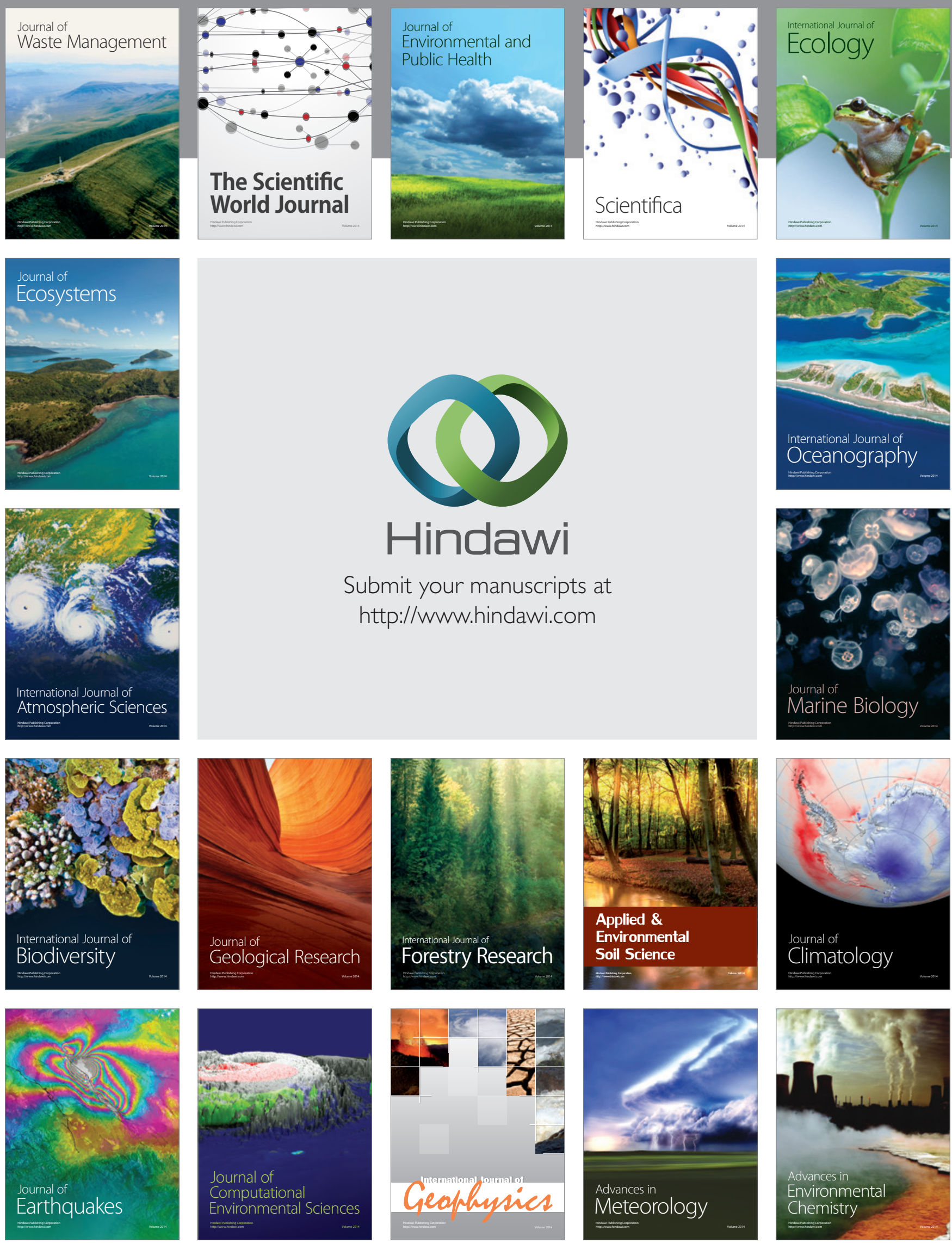